\title{
Anterior cruciate ligament reconstruction: a look at prosthetics - past, present and possible future
}

\author{
Randy Mascarenhas*, Peter B. MacDonald
}

\begin{abstract}
Biological tissue autograft reconstruction using the patellar tendon or quadrupled semitendinosus/gracilis tendons has become the most popular procedure in surgical treatment of a ruptured ACL. This article provides a review of the history of the use of prosthetics with respect to ACL reconstruction grafts including Carbon Fibre, Gore-Tex and Dacron prosthetics as well as the Leeds-Keio Artificial Ligament and the Kennedy Ligament Augmentation Device (LAD). Emphasis is placed on the Ligament Advanced Reinforcement System (LARS) as preliminary investigations of its use have been encouraging. Significant progress has been made recently with respect to the understanding of ACL anatomy, composition, biomechanics, and healing processes, leading to innovative techniques using approaches based in tissue engineering principles and computer - assisted surgery. While research into improved ACL treatment options continues, the synthesis of recent advancements provides a new optimism towards the regeneration of an ACL mirroring its original stability, function, and longevity.
\end{abstract}

KEY WORDS: anterior cruciate ligament, biomaterials, prosthetics, synthetic grafts, tissue engineering

\section{INTRODUCTION}

The anterior cruciate ligament (ACL) is the most frequently injured ligament in the knee and consequently, the majority of research into knee ligament injuries has been directed towards the ACL. While the collateral knee ligaments exhibit strong healing potential and generally respond well to conservative treatment, the anterior cruciate ligament has a poor intrinsic healing ability due to the fact that it is enveloped by synovial fluid and lacks significant vascularization (1). Surgical reconstruction is therefore the most frequent mode of treatment pursued when the $\mathrm{ACL}$ is torn. The patients who experience ACL injuries are significantly younger and more active than those who experience many other orthopaedic injuries. The need for reconstruction options that exhibit longevity in

*To whom correspondence should be addressed:

Randy Mascarenhas

75 Poseidon Bay

Winnipeg Manitoba Canada

R3M 3E4

Email: mascarenhasr@upmc.edu the face of great stresses is therefore imperative (2). Historically, options for surgical treatment have included primary repair with or without synthetic augmentation and reconstruction using either biological tissue grafts or prosthetic ligaments. Primary repairs with or without augmentation have tended to fail at restoring stability to the knee and are not a common treatment option today (3). Likewise, prosthetic replacements have traditionally tended to be inadequate due to post-surgical complications arising from wear and degeneration. Hence, biological tissue autograft reconstruction using the patellar tendon or quadrupled semitendinosus/gracilis tendons has become the most popular procedure in surgical treatment of an ACL rupture. However, the frequency of significant anterior knee pain post-surgically and high occurrence of flexion contracture and crepitation in tendon autografts have kept research interests focused on the further development of prosthetic ligament implants. A significant number of early research endeavours into prosthetic ACL replacements failed due to a poor understanding of the biomechanical and physiological 
properties of the ACL. Tremendous gains in understanding have been made in these areas, with significant progress being made in understanding the inter-dependence between ACL anatomy, tissue composition, biomechanics, and the healing processes. Unfortunately, to date, no prosthesis has proven itself as a viable alternative to the patellar or hamstring tendon autografts, currently used in over $90 \%$ of ACL reconstructions. This article reviews some of the major historical milestones in ACL reconstruction technology and looks forward to the continuing evolution of this technology. The literature used for this review was obtained using the PubMED database with keywords "anterior cruciate ligament" searched in tandem separately with "prosthetics" and "tissue engineering." It should be noted that many of the studies cited in this review obtained funding from orthopaedic and biomaterial companies that sponsored the implant.

\section{SURGICAL REPAIR: ADVANTAGES AND DISADVANTAGES OF BIOLOGICAL TISSUE GRAFTS}

Bone-patellar tendon-bone (BPTB) and semitendinosus/gracilis tendon autografts are currently the most common grafts used in ACL reconstruction. While the BPTB autografts were the former "gold standard", recent studies have identified the quadruple semitendinosus graft as a comparable option for ACL reconstruction (4). Advances in hamstring graft fixation have led to similar strengths of fixation between BPTB and semitendinosus/gracilis grafts (5). Both techniques now offer a high degree of strength and stiffness in the reconstructed ligament. Additionally, use of the patient's own tissue eliminates the risk of rejection and good to excellent results are reported in $85-90 \%$ of patients receiving either of these grafts for ACL reconstructions. Nonetheless, with patellar tendon autografts, many patients experience impaired function and significant morbidity at the donor site including secondary anterior knee pain, patellar tendonitis, infrapatellar contracture, and patellar fracture. Likewise, hamstring weakness and saphenous nerve injury can be seen secondary to hamstring harvest in semitendinosus/gracilis autograft ACL reconstruction (6).

To avoid complications resulting from donor site morbidity in autograft reconstructions, allograft reconstruction has also been examined. While eliminating the donor site morbidity, the use of allografts is not currently considered advantageous due to a limited donor tissue supply, delayed biological incorporation, risks of disease transmission and tissue rejection. In an attempt to overcome these concerns, research into the use of synthetic prosthetic ligaments began over 30 years ago and continues today in hopes of eliminating donor site morbidity and reducing the risk of disease transmission and supply shortages. One of the main obstacles in finding an adequate prosthetic replacement for the ACL is the longevity of the graft, with autogenous tissue consistently proving to be a more durable and long-lasting replacement than the many biomaterials that have been applied to ACL replacement (7).

\section{PROSTHETIC BEGINNINGS AND PAST USE}

The first attempts at a synthetic ACL reconstruction were conducted by Alwyn-Smith in 1918 using silk sutures; they however failed within 3 months (8). Reconstruction with a prosthetic ligament made of polytetrafluoroethylene (PTFE) with embedded carbon or aluminum oxide fibers (Proplast) was first reported in 1973 (9). Results with this system yielded an average time to breakage of just over 1 year. A report by James et al. suggests that only $52 \%$ of reconstructions utilizing this graft yielded satisfactory results (10). Satisfactory results include all grafts that patients were content with and had not ruptured at time of lastest follow-up.

Current classification systems for synthetic replacements of the ACL include grafts, ligament augmentation devices, or total prosthetics. Grafts (polyethylene, PTFE), typically fixed at both ends, were the initial focus of synthetic ACL replacement and were meant to provide stability to the ACL-deficient-knee until secondary reconstruction procedures gained popularity (11). Similarly, ligament augmentation devices (polypropylene, polyester) were intended to provide immediate protection for autogenous tissue grafts until revascularization was complete and the ingrown tissue was capable of withstanding local tensile and compressive forces. Unfortunately, these devices may in fact accomplish the opposite of their intended purpose by stress-shielding autogenous tissue, preventing it from developing adequate mechanical strength. Fixed at both ends like a graft, the total prosthesis was intended as a permanent ACL replacement without any soft-tissue ingrowth that would allow the patient to begin aggressive rehabilitation immediately as no tissue maturation or revascularization was required. While the implantation of a full-strength ACL replacement generally led to excellent short-term results, long-term efficacy results were poor due to wear and ensuing rupture of the prosthesis (11).

Combining the mechanical focus provided by these prior prosthetic approaches with tissue engineering principles has led to the development of a scaffold design intended to serve as a foundation for soft tissue in-growth. Scaffolds may be permanent or may be 
intended to gradually degenerate as the host tissue replaces them. Problems associated with the biological incorporation of scaffolds include variability of tissue in-growth, immature degeneration of the implant and insufficient maturation of the host tissue resulting in an inability of the scaffold to withstand inherent mechanical stresses placed on the ACL. Current directions in this area involve the use of tissue engineering focusing on developing a mechanically and biologically functional matrix for the scaffold and the use of in vitro mechanical signals to guide new tissue development (11). Table 1 summarizes the advantages of the various prosthetic ACL graft options that have been attempted and are discussed below.

\section{CARBON FIBRE PROSTHETICS}

Some of the earliest attempts to discover an appropriate alternative to the biological graft resulted in a variety of carbon fibre prostheses that varied greatly with respect to material and implantation technique. In 1977, Jenkins et al. were the first to use a flexible carbon fibre implant, and suggested that the carbon fibre induced the formation of tendon in animals and humans (12). However, subsequent studies reported the generation and migration of carbon wear particles into the joint space and regional lymph nodes following implantation of the prosthesis (12). To combat this problem, attempts were made to coat the carbon fibre with collagen and absorbable polymers. Of particular interest was a carbon fibre implant proposed by
Alexander et al. coated with a co-polymer of polylactic acid (PLA) and polycapralactone (13). The carbon filaments were thought to act as a scaffold for tissue ingrowth by evenly distributing and reducing the interfacial stress between the implant and soft tissue attachment, while the PLA/polycapralactone would protect the fibre during implantation. Over time, the PLA was meant to resorb and the carbon fibres degrade as new tissue developed, thereby encouraging normal tissue regeneration without permanently replacing it (13). A 24-month study involving 82 patients was conducted by Weiss et al. to further examine the PLA coated prosthesis using a variety of subjective and objective measures (pain, stability, function, and isokinetic strength testing), which revealed significant improvements over the duration of the study (14). Arthroscopic evaluation demonstrated collagenous tissue ingrowth, confirmed by histological studies, to be composed of Type I and III collagen in similar proportions to that found in normal healing ligamentous tissue (14).

A similar design was used in the Surgicraft ABC prosthetic ACL (Surgicraft Ltd., Redditch UK) composed of carbon and polyester fibres oriented in a partial braid by a zig-zag pattern. However, a study by O'Brien et al. with an average follow-up of 34 months showed only 11 of 31 knees (41\%) had good results defined as a Lysholm score greater than 76. The Lysholm knee score is an outcome measure that assesses knee function on a 100 point scale. The

\begin{tabular}{|c|c|c|}
\hline Prosthesis & Advantages & Disadvantages \\
\hline Carbon & $\begin{array}{l}\text { Reduction and even distribution of stress between graft } \\
\text { and soft tissue attachment } \\
\text { Polylactic acid coat protects graft during implantation } \\
\text { Encourages ingrowth of collagen into implant }\end{array}$ & $\begin{array}{l}\text { Migration of carbon wear particles } \\
\text { Unacceptable incidence of implant stretching and rupture } \\
\text { led to poor long-term functional outcomes }\end{array}$ \\
\hline Gore-Tex & Tensile strength $3 \mathrm{X}$ native human ACL & Progressive long-term loosening \\
\hline Dacron & Polyester coating serves to protect implant from abrasion & Poor long-term stability \\
\hline $\begin{array}{l}\text { Leeds-Keio } \\
\text { Artificial } \\
\text { Ligament }\end{array}$ & $\begin{array}{l}\text { Acts as a scaffold for soft tissue ingrowth } \\
\text { Excellent max. tensile strength which } \\
\text { exceeds that of native ACL }\end{array}$ & $\begin{array}{l}\text { Acts as more of a load-bearing prosthesis, } \\
\text { allowing for fibrous tissue ingrowth } \\
\text { Large number of long-term graft ruptures }\end{array}$ \\
\hline $\begin{array}{l}\text { Kennedy } \\
\text { Ligament } \\
\text { Augmentation } \\
\text { Device }\end{array}$ & Protects autogenous graft from excessive stresses & $\begin{array}{c}\text { Weak implant-graft interface } \\
\text { Propensity to cause intra-articular inflam. response } \\
\text { and resulting synovitis and effusions }\end{array}$ \\
\hline LARS Ligament & $\begin{array}{l}\text { Mimics natural ACL structure and orientation } \\
\text { Reduces shearing forces on the implant } \\
\text { Porosity encourages tissue ingrowth }\end{array}$ & $\begin{array}{l}\text { Residual post-operative laxity still present } \\
\text { No long-term follow-up studies yet }\end{array}$ \\
\hline $\begin{array}{l}\text { Tissue-engineered } \\
\text { Scaffolds }\end{array}$ & $\begin{array}{l}\text { Duplicate mechanical \& structural properties } \\
\text { of native ACL } \\
\text { Restoration of normal knee joint kinematics } \\
\text { Implant can resemble normal ACL over time }\end{array}$ & $\begin{array}{l}\text { Loses strength over time } \\
\text { Allogenecity of collagen scaffolds can lead to rejection } \\
\text { Consistent reprod. difficult due to batch-to-batch variability } \\
\text { Collagen not as modifiable as biodegradable polymers }\end{array}$ \\
\hline
\end{tabular}

Table 1: Advantages and disadvantages of various prosthetic ACL grafts. 
authors also noted unacceptable stretching and complete rupture as major complications and concluded that the implant is unsuitable for clinical use (15).

\section{GORE-TEX PERMANENT PROSTHESIS}

The Gore-Tex ligament prosthesis is composed of a single long fiber of expanded polytetrafluoroethylene (PTFE) arranged into loops. Extensive mechanical testing has shown that the resulting ultimate tensile strength is about 3 times that of the human ACL and the results from cyclical creep tests and bending fatigue testing seem to identify Gore-Tex as the strongest synthetic ACL replacement in terms of pure material stability (16). Bolton and Bruchman reported that 129 out of 130 patients receiving a high strength PTFE ligament showed improved knee stability at 15 months or less (16). Glousman et al. reported an initial improvement upon physical examination and subjective scores. However, at mean follow-up of 18 months, they reported a progressive loosening of the prosthesis (17). Similarly, Woods et al. presented 2- and 3-year followup of Gore-Tex ACL reconstructions and showed a similar pattern of early improvement post-operatively, but deterioration over time. They reported an overall failure rate of $33 \%$ at 3-year follow-up (18). Indelicato et al.'s follow-up of Gore-Tex implant ACL reconstructions showed a $90 \%$ success rate at 2 years versus only a $76 \%$ success rate at 3 years or more (19). Despite similar reports describing complications with the Gore-Tex ACL prosthesis, subjective results in several studies remain acceptable at $60-80 \%(17,19)$. The Gore-Tex ACL prosthesis is currently FDA approved for use in patients who have had a failed autogenous intra-articular graft procedure.

\section{DACRON}

With its success as a vascular surgery implant (20), various forms of Dacron grafts have been developed as a scaffold for ACL replacements. The implant is a composite of four tightly woven polyester strips wrapped in a sheath of loosely woven velour, designed to minimize abrasion of the graft and act as a scaffold for fibrous tissue ingrowth. A report by Lukianov et al. reviewed the short-term follow-up (mean 28 months) of 41 patients who underwent ACL reconstruction with the Stryker Dacron ligament prosthesis (3). Seventy-five percent of the patients were found to have a negative Lachman, anterior drawer, and pivot shift at their most recent follow-up. However, Richmond et al. reported failure rates of $37.1 \%$ in a study of Dacron reconstruction with mean long-term follow-up of 50 months (21). Likewise, Barrett et al. reported higher failure rates of $47.5 \%$ after a four-year follow-up period (22). A clinical study by Lopez-Vazquez et al. examining ACL reconstruction with a Dacron prosthesis showed a similar deterioration of results after the first post-operative year (23). With the initial short-term strength shown by these grafts offset by their poor longterm stability, Dacron grafts should not be considered a viable alternative for $\mathrm{ACL}$ reconstruction.

\section{LEEDS-KEIO ARTIFICIAL LIGAMENT}

With the desire to design a graft that combined the properties of a permanent prosthesis and a tissuepromoting scaffold, Fujikawa and Seedhom developed the Leeds-Keio artificial ligament: a polyester meshlike structure anchored to the femur and tibia with bone plugs (24). This mesh was intended as a scaffold for soft tissue ingrowth through the intra-articular and extra-articular sections of the ligament, eventually uniting the bone plugs. The implant was considered sufficiently flexible to be effective with a maximal tensile strength of approximately 2100 Newtons (N), which significantly exceeds that of the average young adults' natural ACL (about $1730 \mathrm{~N}$ ) (24). Initial descriptions from the inventors also described minimal articular wear with the ligament (24). The inventors of this graft have reported successful clinical results with arthroscopic observations documenting neoligamentous tissue within the implanted Dacron scaffold. Other investigators, however, have reported the ingrowth of non-aligned fibrous tissue (i.e. non-neoligamentous tissue) within the device after implantation and suggested that the Leeds-Keio ligament did not serve as a true scaffolding graft, but instead behaved as a permanent load-bearing prosthesis, subject to long-term failure in the joint (25).

McLoughlin and Smith presented a 3.8 year follow-up study of 25 patients implanted with the Leeds-Keio ligament for chronic ACL instability. They reported a low complication rate and considerable success in the elimination of instability after finding good postoperative results with the anterior drawer test using an arthrometer at $90^{\circ}$ of flexion (26). Nevertheless, ensuing long-term follow-up studies showed a deterioration of results after the first post-operative year and a large number of long-term graft ruptures despite excellent early results in stability testing and on the Lysholm scale (27). These findings were similar to earlier results reported by Schindhelm, who found that good early results in a sheep model were not maintained (28). Due to the number of long-term graft ruptures and the lack of long-term stability provided, the Leeds-Keio ligament is no longer suitable for reconstruction of the human $\operatorname{ACL}(27,28)$. 


\section{KENNEDY LIGAMENT AUGMENTATION DEVICE (LAD)}

Kennedy et al. introduced the concept of the Ligament Augmentation Device (LAD) in 1980 (29). The graft, composed of a band-like braid of polypropylene, was originally developed to reinforce the area of pre-patellar tissue considered to be a weak area of autogenous patellar tendon grafts. Use of this prosthesis employed the MacIntosh/Marshall transfer of a portion of the rectus femoris tendon, pre-patellar tissue, and central third of the patellar tendon in an over-the-top fashion (30). Originally, the graft was developed to protect the autogenous tissue graft from excessive stresses during the initial remodelling phase (characterized by degeneration and revascularization), allowing for earlier resumption of pre-operative activity levels (29). Research has shown that the percentage of load accepted by the LAD varies according to the type of graft employed and method of reconstruction. Comparisons of the patellar tendon and semitendinosus/gracilis LAD composite grafts revealed that the LAD will accept approximately $28 \%$ and $45 \%$ of the applied load, respectively (31). To prevent excessive stress shielding that would otherwise prevent the autogenous tissue from developing a normal functional tensile strength, the LAD was attached to the bone at only one end. Despite a promising beginning, the suture interface between the LAD and the graft was identified as the weak link of the composite.

Whether collagen fibres become truly incorporated into the LAD remains a controversial issue. Most histological evidence has been derived from animal studies and thus may not be fully indicative of results in humans. Nevertheless, this evidence seems to point to adequate longitudinal collagenization of the graft with inconclusive results on whether or not collagen ingrowth within the LAD has occurred (32). Furthermore, as an intra-articular foreign body, the LAD has been reported to induce an inflammatory response characterized by foreign body giant cells and macrophages in the surrounding tissue. A review by Kumar et al. reported that the majority of complications seen following use of the LAD were characterized as effusions and reactive synovitis, likely a result of LADinduced inflammatory response (23). The decline in use of the aforementioned MacIntosh/Marshall transfer, combined with the weak graft-prosthetic suture interface and propensity of the LAD to cause high rates of post-operative synovitis have resulted in a lack of widespread use of the device.

\section{THE FUTURE: LIGAMENT ADVANCED REINFORCEMENT SYSTEM (LARS) ARTIFICIAL LIGAMENT}

The Ligament Advanced Reinforcement System (LARS) (Arc-sur-Tille, France) artificial ligament consists of fibres made of polyethylene terephthalate (PET). An intra-osseous segment is composed of longitudinal fibres bound together by a transverse knitted structure while an intra-articular segment is composed of parallel longitudinal fibres twisted at $90^{\circ}$. The main innovation of this artificial ligament lies in its ability to mimic the natural ligamentous structure and reduce shearing forces by orientating the free fibers of the intra-articular portion of the graft clockwise or counter-clockwise for use in right and left knees, respectively. Furthermore, the PET fibres of the intraarticular segment are designed to encourage tissue ingrowth due to the porosity of the material, allowing ingrowth from the surrounding osseous tunnels. Ideally, such tissue ingrowth between the ligament fibres would contribute to the viscoelasticity of the graft and protect against friction at the opening of the bony canal and between the fibres themselves (1).

A study by Lavoie et al. examined ACL reconstruction with the use of the LARS artificial ligament. Thirtyeight of forty-seven patients suffered from chronic ruptures of the ACL, while nine others presented with acute or subacute ruptures at a mean follow-up of 21.9 months. Six patients had previously had an unsuccessful ACL reconstruction. The Knee Osteoarthritis Outcome Score (KOOS) was administered to assess patients' opinions regarding their knee, while a modified International Knee Documentation Committee (IKDC) scoring system was used to examine knee stability. The IKDC form initially consisted of seven knee-related parameters that were each rated as either normal, nearly normal, abnormal, and severely abnormal. The worst score amongst the seven categories determined the final score. The form was later modified in 2001 to include subjective factors such as symptoms, sports activities, and ability to function. The Tegner activity scale, a subjective ten point activity scale, was obtained to assess patient activity levels. A Telos radiographic stress system was used to examine anterior knee displacement, which involves obtaining radiographs with the knee in ninety degrees of flexion and a posterior force applied to the knee. When results are compared to the normal knee, this test helps in the assessment of post-operative laxity in the reconstructed knee which may indicate that the graft is failing. None of the patients presented symptoms of synovitis, but longer follow-up time is required to properly draw conclusions with respect to patient outcome. Although Tegner scores improved 
significantly following surgery, no patients returned to pre-injury activity levels. Data obtained by the KOOS demonstrated patient satisfaction ranged from 73.5 to $93.0 \%$. In comparison to the uninjured knee, postoperative Telos stress radiography and the Lachman test indicated an average posterior-anterior displacement of $7.3 \mathrm{~mm}$ for the involved knee (28).

A more complete examination of the LARS artificial ligament was provided in a subsequent study by the same authors. Nau et al. conducted a two-year followup randomized controlled trial that compared the BPTB autograft with the LARS artificial ligament method of ACL reconstruction in 53 patients with chronic instability (1). Like the preceding study, assessments included clinical examination, anterior laxity testing, as well as the KOOS, IKDC, and Tegner scores. In particular, IKDC evaluation revealed little significant difference between the two methods. Follow-up values for instrumented laxity testing were greater in the LARS group. While similar overall results were obtained for both groups, these results may suggest that a full return to activity may be hastened by using the LARS artificial ligament rather than the conventional BPTB technique (1).

Another recent study by Talbot et al. examined the use of the LARS artificial ligament for ligament reconstruction in knee dislocations (2). Twenty patients were included with a mean follow-up of 27.4 months. Each patient was evaluated using the Lysholm score, underwent clinical examination to identify ligamentous laxity and range of motion, and completed the ACL quality of life (ACL-QoL) questionnaire. The mean Lysholm score was 71.7, which is lower than scores reported by several other studies (range of 74.7 to 91.3 ) investigating the outcomes of knee dislocations treated with surgery as reported by Fanelli (35). Following the same trend, Telos radiometry revealed a mean residual laxity of $5 \mathrm{~mm}$ in patients post-surgery, which is also greater than these previously reported results. The average range of motion post-surgery was $118^{\circ}$ with a mean fixed flexion contracture of $2^{\circ}(2)$.

Although preliminary investigations into the use of the LARS artificial ligament have been encouraging, concerns regarding the risk of rupture remain and must be addressed through long-term follow-up studies.

\section{TISSUE ENGINEERING ADVANCES}

Permanent synthetic prostheses are capable of duplicating the mechanical and structural properties of the ACL. However, they generally tend to lose strength with time. Tissue-based or tissue-aided implants offer the additional possibility of the restoration of normal joint kinematics while the mechanical behaviour of these implants is expected to improve over time as tissues are remodelled within the knee (36). An ideal ACL scaffold must meet the immediate functional mechanical demands within the reconstructed knee, however, they must also degrade at a rate similar to that of tissue ingrowth. Accordingly, the ACL scaffold should lose its mechanical integrity while allowing the remodelled tissues to gain strength and accept an increasing amount of the mechanical demands placed on the ACL. Current research into this novel tissueengineering approach has focused on seeding either collagen-based scaffolds or synthetic biodegradable polymers with a variety of different cell types. In hopes of stimulating early healing, reducing biomaterialrelated inflammatory response and improving neoligament formation, several researchers have sought to adopt a cell sheeting technique to improve the performance of the synthetic ACL scaffold.

Several groups have conducted experiments on this tissue-engineered approach to ACL ligament reconstruction using both fibroblast-seeded synthetic scaffolds and collagen-based prosthetics $(37,38)$. Bellincampi et al. measured the ingrowth characteristics of rabbit fibroblasts on skin and ACL scaffolds (39). Subsequent in vivo studies suggested that fibroblastseeded collagen scaffolds were viable after reimplantation into the donor rabbit. The major limitations of these approaches are the allogenicity of the collagen scaffolds, often leading to further complications. Collagen-based constructs also suffer from batch-to-batch variability, making consistent reproduction of these prostheses difficult. Collagen does not offer the same flexibility for modification that is reported with the technology of biodegradable polymers (6).

As an alternative to the scaffolds made of nondegradable polymers, investigators have begun to examine biodegradable materials that would provide immediate stabilization to the repaired ligament but would also act as a scaffold for the ingrowth and/or replacement by host cells. Cao et al. described the generation of neo-tendons in a nude mice model by implanting polyglycolic acid (PGA) scaffolds seeded with bovine tendon fibroblasts in the subcutaneous space of athymic mice (40). Using a similar system, Koski et al. reported the formation of ligament-like structures when fibroblasts isolated from bovine cruciate ligaments were seeded onto PGA scaffolds and implanted subcutaneously in nude mice (6). In both studies, the tissue developed histological characteristics similar to normal tendon and ligament over time.

Ouyang et al. reported that bone marrow stromal cells (bMSCs) seeded onto poly-lactic and -glycolic acid (PLGA) scaffolds grew as a multi-layer of cells intertwined in a collagen matrix synthesized by the cells 
themselves. They also noted that the cell sheet formed faster than scaffolds seeded with terminally differentiated cells, such as fibroblasts and smooth muscle cells (41). They reported that degradation of the scaffolds occurred over time, as indicated by a decrease in failure load. Altman et al. seeded 6-cord silk scaffolds with human bone marrow stromal cells and cultured them for 14-21 days. Their results similarly suggested a slow degradation of the scaffolds. However, fatigue analysis and subsequent regression analysis revealed an expected matrix lifetime equivalent to 1 year in vivo. While these reports are an estimate, the authors suggest that this is a marked improvement compared to similar studies using collagen scaffolds (36).

The future of tissue engineering may also require a significant contribution from cell-specific growth factors influencing the maturation and homeostasis of the healing response of ligament tissue. Studies have suggested that individual growth factors may have an important effect on cell division and enhance ligament healing, while others have pointed to the synergistic effect of a combination of growth factors as important to cell outgrowth in ACL explants $(42,43)$. In a study observing the effects of several growth factors on the cell migration, proliferation and collagen production in human ACL cells, Murray et al. suggested that specific dose-response relationships may exist for the optimal activity of each growth factor (44). These authors observed that the addition of transforming growth factor (TGF) $\beta-1$ led to an increased cell population, as well as increased collagen and smooth muscle actin production in human ACL cells cultured on top of a collagenglycosaminoglycan scaffold. Despite the complex nature of the inter-dependent factors at play during the recovery and rehabilitative period following an ACL reconstruction, much of the literature today suggests that tissue engineering techniques will lead to a new generation of ACL replacements, capable of regenerating a mechanically robust and natural ACL.

\section{COMPUTER-ASSISTED ACL RECONSTRUCTION}

In an attempt to improve the accuracy and reproducibility of ACL graft placement, several groups have turned to computer-assisted surgery in an attempt to reduce the incidence of graft failure $(45,46)$. These systems are capable of modeling the placement and predicting the impingement of an ACL graft based on intra-operative anatomical landmarks and signals received at an opto-electric camera. These studies reported that experience level did not affect the placement of the tunnels. Computer-assisted ACL replacement reduces variance in tunnel placement and allows residents and less experienced surgeons to limit complications and control tunnel positioning (46). Based on the success of navigation systems for total knee and hip replacements, the use of computer-assisted ACL reconstruction may lead to similarly dramatic improvements in technical and functional outcomes.

\section{CONCLUSION}

Satisfactory prosthetic replacement of the ACL has been a focus of orthopaedic research endeavours for the past thirty years. Desires to provide immediate mobility and strength to the ACL-deficient knee while avoiding the donor site morbidity caused by the commonly used autograft surgical techniques continually drive new research initiatives. Most of the grafts that have been developed to date have failed due to unsatisfactory long-term physiologic and functional performance. Most permanent ACL prostheses are prone to creep, fatigue, and mechanical failure within several years after implantation (40). Tissue ingrowth scaffolds and ligament augmentation devices require further refinement to provide effective mechanical support while avoiding stress-shielding of the host tissue. In view of these factors, prosthetics are not widely used today in ACL reconstruction, and autogenous tissue grafts remain the gold standard used by the majority of surgeons. Perhaps development of resorbable, tissueinducing and cell-seeded biomaterials will improve the long-term biomechanical performance of the reconstructed anterior cruciate ligament. Advances in tissue engineering combined with developments in molecular biology and gene therapy may couple with the rapid gains in computer-assisted surgery to provide improved options for the ACL-deficient knee, with a greater potential to restore its pre-injury state.

\section{REFERENCES}

1. Nau T, Lavoie P, Duval N, A new generation of artificial ligaments in reconstruction of the anterior cruciate ligament. Two-year follow-up of a randomised trial. J Bone Joint Surg Br., 2002. 84(3): p. 356-60.

2. Talbot M, Berry G, Fernandes J, Ranger P, Knee dislocations: experience at the Hopital du Sacre-Coeur de Montreal. Can J Surg., 2004. 47(1): p. 20-4.

3. Lukianov AV, Richmond JC, Barrett GR, Gillquist J, A multicenter study on the results of anterior cruciate ligament reconstruction using a Dacron ligament prosthesis in "salvage" cases. Am J Sports Med., 1989. 17(3): p. 380-5.

4. Krudwig WK, Anterior cruciate ligament reconstruction using an alloplastic ligament of polyethylene terephthalate (PET -Trevira -- hochfest). Follow-up study. Biomed Mater Eng., 2002. 12(1): p. 59-67.

5. Lidén M, Ejerhed L, Sernert N, Laxdal G, Kartus J, Patellar tendon or semitendinosus tendon autografts for anterior cruciate ligament reconstruction: a prospective, randomized study with a 7-Year follow-up. Am J Sports Med. 2007 May;35(5):740-8.

6. Koski JA, Ibarra C, Rodeo SA., Tissue-engineered ligament: 
cells, matrix, and growth factors. Orthop Clin North Am., 2000. 31(3): p. 437-52.

7. Petrigliano FA, McAllister DR, Wu BM, Tissue engineering for anterior cruciate ligament reconstruction: a review of current strategies. Arthroscopy. 2006 Apr;22(4):441-51.

8. Burnett QM 2nd, Fowler PJ, Reconstruction of the anterior cruciate ligament: historical overview. Orthop Clin North Am. 1985 Jan;16(1):143-57.

9. Ahlfeld SK, Larson RL, Collins HR, Anterior cruciate reconstruction in the chronically unstable knee using an expanded polytetrafluoroethylene (PTFE) prosthetic ligament. Am J Sports Med. 1987 Jul-Aug;15(4):326-30.

10. James SL, Kellam JF, Slocum DB, Larsen RL, The proplast prosthetic ligament stent as a replacement for the cruciate ligaments of the knee. Aktuelle Probl Chir Orthop., 1983. 26(116-20).

11. Woods, GW, Synthetics in anterior cruciate ligament reconstruction: a review. Orthop Clin North Am., 1985. 16(2): p. 227-35.

12. Jenkins, DHR, The repair of cruciate ligaments with flexible carbon fibre: A longer term study of the induction of new ligaments and of the fate of the implanted carbon. J Bone Joint Surg Br., 1978. 60-B(4): p. 520-2.

13. Alexander H, Weiss AB, Parsons JR., Absorbable polymerfilamentous carbon composites--a new class of tissue scaffolding materials. Aktuelle Probl Chir Orthop., 1983. 26: p. 78-91.

14. Weiss, AB, Blazina ME, Goldstein AR, Alexander H, Ligament replacement with an absorbable copolymer carbon fiber scaffold--early clinical experience. Clin Orthop., 1985. 196(77$85)$.

15. Mody BS, Howard L, Harding ML, Parmar HV, Learmonth DJ, The $\mathrm{ABC}$ carbon and polyester prosthetic ligament for ACLdeficient knees. Early results in 31 cases. J Bone Joint Surg Br. 1993 Sep;75(5):818-21.

16. Bolton $\mathrm{CW}$, Bruchman WC, The GORE-TEX expanded polytetrafluoroethylene prosthetic ligament. An in vitro and in vivo evaluation. Clin Orthop., 1985. 196: p. 202-13.

17. Glousman R, Shields C Jr, Kerlan R, et al., Gore-Tex prosthetic ligament in anterior cruciate deficient knees. Am J Sports Med., 1988. 16(4): p. 321-6.

18. Woods GA, Indelicato PA, Prevot TJ, The Gore-Tex anterior cruciate ligament prosthesis. Two versus three year results. Am J Sports Med., 1991. 19(1): p. 48-55.

19. Indelicato PA, Pascale MS, Huegel MO, Early experience with the GORE-TEX polytetrafluoroethylene anterior cruciate ligament prosthesis. Am J Sports Med., 1989. 17(1): p. 55-62.

20. Arnoczky SP, Warren RF, Minei JP, Replacement of the anterior cruciate ligament using a synthetic prosthesis. An evaluation of graft biology in the dog. Am J Sports Med. 1986 JanFeb;14(1):1-6.

21. Richmond JC, Manseau CJ, Patz R, McConville O, Anterior cruciate reconstruction using a Dacron ligament prosthesis. A long-term study. Am J Sports Med., 1992. 20(1): p. 24-8.

22. Barrett GR, Lawrence L Jr, Shelton WR, Manning JO, Phelps R, The Dacron ligament prosthesis in anterior cruciate ligament reconstruction. A four-year review. Am J Sports Med., 1993. 21(3): p. 367-73.

23. Lopez-Vazquez E, Juan JA, Vila E, Debon J, Reconstruction of the anterior cruciate ligament with a Dacron prosthesis. J Bone Joint Surg Am., 1991. 73(9): p. 1294-300.

24. Fujikawa K, Iseki F, Seedhom BB, Arthroscopy after anterior cruciate reconstruction with the Leeds-Keio ligament. J Bone Joint Surg Br., 1989. 71(4): p. 566-70.

25. Macnicol MF, Penny IA, Sheppard L, Early results of the LeedsKeio anterior cruciate ligament replacement. J Bone Joint Surg
Br., 1991. 73(3): p. 377-80

26. McLoughlin SJ, Smith RB, The Leeds-Keio prosthesis in chronic anterior cruciate deficiency. Clin Orthop., 1992. 283: p. 215-22.

27. Rading J, Peterson L, Clinical experience with the Leeds-Keio artificial ligament in anterior cruciate ligament reconstruction. A prospective two-year follow-up study. Am J Sports Med., 1995. 23(3): p. 316-9.

28. Schindhelm K, Rogers GJ, Milthorpe BK, et al., Autograft and Leeds-Keio reconstructions of the ovine anterior cruciate ligament. Clin Orthop., 1991. 267: p. 278-93.

29. Kennedy JC, Roth JH, Mendenhall HV, Sanford JB, Presidential address. Intraarticular replacement in the anterior cruciate ligament-deficient knee. Am J Sports Med., 1980. 8(1): p. 1-8.

30. Zoltan DJ, Reinecke C, Indelicato PA, Synthetic and allograft anterior cruciate ligament reconstruction. Clin Sports Med., 1988. 7(4): p. 773-84.

31. Hanley P, Lew W, Lewis JL, Hunter RE, Kirstukas S, Kowalczyk C, Load sharing and graft forces in anterior cruciate ligament reconstructions with the Ligament Augmentation Device. Am J Sports Med., 1989. 17(3): p. 414-22.

32. Kdolsky RK, Gibbons D, Kwasny O, Schabus R, Plenk H Jr, Braided polypropylene augmentation device in reconstructive surgery of the anterior cruciate ligament: long-term clinical performance of 594 patients and short-term arthroscopic results, failure analysis by scanning electron microscopy, and synovial histomorphology. J Orthop Res., 1997. 15(1): p. 1-10.

33. Kumar K, Maffulli N, The ligament augmentation device: an historical perspective. Arthroscopy, 1999. 15(4): p. 422-32.

34. Lavoie P, Fletcher J, Duval N, Patient satisfaction needs as related to knee stability and objective findings after ACL reconstruction using the LARS artificial ligament. Knee, 2000. 1(7): p. 157-63.

35. Fanelli GC, Evaluation and treatment of the multiple ligament injured knee. Arthroscopy. 2003 Dec;19 Suppl 1:30-7.

36. Altman GH, Horan R, Lu HH, Moreau J, Martin I, Richmond JC, Kaplan DL, Silk matrix for tissue engineered anterior cruciate ligaments. Biomaterials., 2002. 23(20): p. 4131-41.

37. Bourke SL, Kohn Joachim, Dunn MG, Preliminary development of a novel resorbable synthetic polymer fiber scaffold for anterior cruciate ligament reconstruction. Tissue Eng., 2004. 10(1-2): p. 43-52.

38. Caruso, AB, Dunn MG, Changes in mechanical properties and cellularity during long-term culture of collagen fiber ACL reconstruction scaffolds. J Biomed Mater Res A, 2005. 73(4): p. 388-97.

39. Bellincampi LD, Closkey RF, Prasad R, Zawadsky JP, Dunn MG, Viability of fibroblast-seeded ligament analogs after autogenous implantation. J Orthop Res., 1998. 16(4): p. 414-20.

40. Cao Y, Vacanti J, Ma X, et al., Generation of neo-tendon using synthetic polymers seeded with tenocytes. Transplant Proc., 1994. 26(6): p. 3390-2.

41. Ouyang, HW, Toh SL, Goh J, Tay TE, Moe K, Assembly of bone marrow stromal cell sheets with knitted poly (L-lactide) scaffold for engineering ligament analogs. J Biomed Mater Res B Appl Biomater, 2005. 75B(2): p. 264-271.

42. Lee J, Green MH, Amiel D, Synergistic effect of growth factors on cell outgrowth from explants of rabbit anterior cruciate and medial collateral ligaments. J Orthop Res., 1995. 13(3): p. 43541.

43. Schmidt CC, Georgescu HI, Kwoh CK, Blomstrom GL, Engle CP, Larkin LA, Evans CH, Woo SL, Effect of growth factors on the proliferation of fibroblasts from the medial collateral and anterior cruciate ligaments. J Orthop Res., 1995. 13(2): p. 18490.

44. Murray MM, Rice K, Wright RJ, Spector M, The effect of 
selected growth factors on human anterior cruciate ligament cell interactions with a three-dimensional collagen-GAG scaffold. J Orthop Res, 2003. 21(2): p. 238-44.

45. Muller-Alsbach, UW, Staubli, AE, Computer aided ACL reconstruction. Injury, 2004. 35 Suppl 1: p. S-A65-7.

46. Schep NW, Stavenuiter MHJ, Diekerhof CH, et al., Intersurgeon variance in computer-assisted planning of anterior cruciate ligament reconstruction. Arthroscopy, 2005. 21(8): p. 942-7.

Randy Mascarenhas (MD, 2007) is a post-doctoral orthopaedic research fellow at the University of Pittsburgh Medical Center, Department of Orthopaedic Surgery. He received a B.Sc. in Science from the University of Manitoba in 2003. He is currently conducting research in orthopaedic sports medicine at the University of Pittsburgh and plans to enter residency training in orthopaedic surgery at the conclusion of his research fellowship.

Peter B. MacDonald (MD, 2007) is the Gibson Professor and Head of Orthopaedic Surgery at the University of Manitoba. He completed a B.Sc, MD, and orthopaedic residency training at the University of Manitoba, and an orthopaedic sports medicine fellowship at the University of Western Ontario. His interests lie in research and arthroscopic/reconstructive treatment of disorders of the shoulder and knee. 